\title{
Synthesis of Electroconducting Hydroxy-Sodalite/Graphite Composite: Preparation and Characterization
}

\author{
Rima Alomari1*, Muayed Esaifan², Mohammed Khair Hourani1, Hiba Al Amayreh³, \\ Mohammed Amayreh", Hani Khoury4 \\ ${ }^{1}$ Department of Chemistry, The University of Jordan, Amman, Jordan \\ ${ }^{2}$ Department of Chemistry, Faculty of Arts and Sciences, University of Petra, Amman, Jordan \\ ${ }^{3}$ Department of Physics and Basic Science, Faculty of Engineering Technology, Al-Balqa Applied University, Amman, Jordan \\ ${ }^{4}$ Department of Geology, The University of Jordan, Amman, Jordan \\ Email: *reema.hmo@gmail.com
}

How to cite this paper: Alomari, R., Esaifan, M., Hourani, M.K., Al Amayreh, H., Amayreh, M. and Khoury, H. (2019) Synthesis of Electroconducting Hydroxy-Sodalite/Graphite Composite: Preparation and Characterization. Advances in Materials Physics and Chemistry, 9, 25-36. https://doi.org/10.4236/ampc.2019.93003

Received: February 27, 2019

Accepted: March 12, 2019

Published: March 15, 2019

Copyright (อ 2019 by author(s) and Scientific Research Publishing Inc. This work is licensed under the Creative Commons Attribution International License (CC BY 4.0).

http://creativecommons.org/licenses/by/4.0/

\section{(c) (i) Open Access}

\begin{abstract}
Electroconductive hydroxy-sodalite/graphite composites were synthesized by alkali-activation of kaolinite in the presence of sodium hydroxide as the alkali activator and graphite as a conductive filler. Thermal, morphological and microstructural properties in addition to direct current (D.C.) conductivity of the prepared composites were investigated. Thermogravimetric analysis (TGA), Fourier transform infrared spectroscopy in the attenuated total reflection mode (FTIR/ATR), X-ray diffraction (XRD), scanning electron microscope/energy dispersive using X-ray analysis (SEM/EDX) and DC conductivity measurements were used to characterize the prepared composites. The effect of the hydroxyl-sodalite-to-graphite and $\mathrm{NaOH}$-to-kaolinite ratios on the electrical conductivity was investigated and evaluated on the generated composite specimens made of Jordanian kaolinite or pure kaolinite. It was demonstrated that increasing the mass ratio of graphite-to-kaolinite in the clay-based composites increased the electrical conductivity of the resultant composites. It was also observed that using 1:1 graphite-to-pure kaolinite mass ratio showed the best electrical conductivity value of $3 \times 10^{-3} \mathrm{~s} / \mathrm{cm}$, among the other mass ratios used for pure kaolinite specimens, while using 1:1 mass ratio of graphite-to-Jordanian kaolinite showed a conductivity of 1.6 $\mathrm{s} / \mathrm{cm}$.
\end{abstract}

\section{Keywords}

Kaolinite, Graphite, Composite Inorganic Polymers, Electroconductive Composites 


\section{Introduction}

Inorganic polymers are macromolecules comprising of inorganic elements as part of their skeletal structure or as pendent functionality within a dimensional skeletal structure [1]. The term inorganic polymer is more often used to specify polymers without carbon atoms in their skeletal structures. Inorganic polymers have attracted the attention of researchers on the unique properties of the inorganic counterpart in the polymer as compared to their organic counterparts [2]. The excellent features of the inorganic polymers include high thermal stability, inexpensive versatile sources, high mechanical strength, and the ability to be manufactured in chains, sheets and three-dimensional structures [2] [3].

Kaolinite is a layered aluminosilicate mineral with the chemical composition of $\mathrm{Al}_{2} \mathrm{Si}_{2} \mathrm{O}_{5}(\mathrm{OH})_{4}$. It has low swell-shrink and cation-exchange capacities (1 - 15 meq/100 g) [3]. It has been activated by alkali-activation to produce, potentially, a network of hydroxy-sodalite (H-SOD) [4].

The reaction of solid aluminosilicate sources, such as kaolinite, with an aqueous alkali hydroxide or silicate solution can produce a synthetic alkali activated aluminosilicate material, which is called inorganic polymers. Sources of solid aluminosilicate include natural minerals such as kaolinites and industrial wastes such as fly-ash and slag from blast furnaces [5]. The alkali activation reaction is $\mathrm{pH}$ sensitive and $\mathrm{NaOH}$ or $\mathrm{KOH}$ may have been frequently used for this specific purpose [6] [7].

Hydroxy-sodalite is a crystalline form of aluminosilicate network comprising of diverse ordered channels, sizes and infinite structures [4] [8]. This particular channel-like structure is responsible for many applicable properties of the H-SOD, such as molecular sieving [9], catalytic activities [10], ion exchange [11], and high selectivity for adsorption [12] [13]. Using naturally occurring aluminosilicate materials such as kaolinite can reduce further $\mathrm{CO}_{2}$ emissions produced from thermally activated aluminosilicates [14]. Aluminosilicate polymers have many enticing properties such as malleability, and ability to be molded in various complex shapes and to be intercalated with different conductive additives, such as carbon nanotubes, graphite powder and metal nanowires [15].

Graphite, on the other hand, has a two-dimensional carbon skeletal structure, famed with lubricating and electrical properties and is commercially made from charcoal or coke. Intercalating compounds with graphite can give superior metallic anisotropic properties [16] [17]. In the unique sandwiched structure, the host atom or molecule is located between the graphite layers, generating compounds with variable stoichiometries in which the atoms are covalently bonded in the plane with only three of the four potential bonding sites persuaded. The fourth electron is left free to travel through the planes of the carbon layers in graphite, providing vast electron delocalization; hence electrical conductivity. Graphite is the most stable form of carbon-based structure under standard conditions and has high thermal stability and high electrical conductivity. These desirable properties have led to its widespread utilization in high temperature ma- 
terial manufacturing applications [18] [19].

Electrically conductive clay-based materials are acquiring a substantial debate due to their superior properties over their metallic electroconductive analogues [15] [20]. They have attracted great attention in many industrial and scientific areas because of their high chemical, thermal and wear resistances and high mechanical strength as compared to the traditional metal-based electroconductive materials. Moreover, electroconductive clays have a potential to provide higher electrical sensitivity since they have been served as ensemble of microarrays or ultramicroelectrodes, which enhanced the signal and lowered the background noise [15] [21]. The electroconductive polymers prepared with aluminosilicate materials might be tailored to specific industrial applications by incorporating conventional functional groups into the aluminosilicate matrix. The resulted materials are of a salutary hybrid since it combines the high mechanical strength of aluminosilicates and the electroconductivity of the filling additives in the material structure. The electrical conductivity of the clays is more often evaluated on a rectangular or cylindrical specimen to affirm the bearing of a uniform electric filed in the specimen material [21] [22] [23].

In this study, the synthesis of a hydroxy-sodalite/graphite composite was done by an alkali activation of kaolinite. The reaction was conducted at a low temperature and pressure in the presence of sodium hydroxide as the alkali activator. The effect of the hydroxyl-sodalite-to-graphite and $\mathrm{NaOH}$-to-kaolinite ratios on the electrical conductivity was investigated and evaluated on the generated composite specimens made of Jordanian kaolinite or pure kaolinite.

\section{Materials and Experimental}

\subsection{Preparation of Materials and Standards}

Jordanian kaolinite rich clay (coded as JK) was collected from Batn elgoul (south of Jordan). As a reference, pure kaolinite clay (coded as PK) was supplied by Merck KGaA (99.99\% minimum purity, Germany). Graphite powder with an average diameter size $\leq 150 \mu \mathrm{m}$ (99.99\% minimum purity, Sigma Aldrich) was used as the conductive phase in the composite. The alkaline activating solution was prepared by adding a certain amount of $\mathrm{NaOH}$ pellets ( $98 \%$ pure, Merck KGaA, Germany) to Milli-Q integral water in a capped plastic bottle. The sodium hydroxide solution was left to cool down to ambient temperature prior to use.

The graphite/kaolinite powder with different mass ratios was mixed thoroughly with $\mathrm{NaOH}$ solution, as listed in Table 1 . To ensure enough workability and stability for molding and de-molding of the specimens, a planetary mixer (Hobart A200) was used at $198 \mathrm{rpm}$ for $10 \mathrm{~min}$. The formed viscous dark mixture was molded immediately in a stainless steel cylindrical mould (with a diameter of $2.5 \mathrm{~cm}$ ) using a hydraulic press at a pressure of $5-6 \mathrm{MPa}$. The dimensions of the specimens after hydraulic pressing were measured using a digital caliber to be nearly $18-23 \mathrm{~mm}$ in height. The molded specimens were then cured 
Table 1. The mass ratios of the components of PK and JK based H-SOD/graphite composites where $\mathrm{P} 1-\mathrm{P} 4$ are codes referring to $\mathrm{PK}$ based $\mathrm{H}-\mathrm{SOD} /$ graphite composites and T1-T4 are referring to JK H-SOD/graphite composites.

\begin{tabular}{cccc}
\hline \multirow{2}{*}{ Composite } & \multicolumn{3}{c}{ Mass ratios } \\
\cline { 2 - 4 } & Graphite/PK or JK & NaOH/kaolinite & $\mathrm{H}_{2} \mathrm{O} /$ kaolinite \\
\hline P1 & 0.25 & 0.1 & 0.1 \\
P2 & 0.50 & 0.2 & 0.2 \\
P3 & 0.75 & 0.3 & 0.3 \\
P4 & 1.00 & 0.4 & 0.4 \\
T1 & 0.25 & 0.1 & 0.1 \\
T2 & 0.50 & 0.2 & 0.2 \\
T3 & 0.75 & 0.3 & 0.3 \\
T4 & 1.00 & 0.4 & 0.4 \\
\hline
\end{tabular}

in an oven (Heraeus model TU100/150) at $75^{\circ} \mathrm{C}$, which is well below the boiling point of water, for 2 - 3 days to prevent the high vapor pressure of water which may disrupt the specimens and affect the strength of the composite body.

\subsection{Characterization of the Raw Materials and Prepared Composites}

The chemical compositions of the pure and Jordanian kaolinites, graphite powder and the resulted inorganic polymer composites were examined on fused pellets using Shimadzu XRF-1800 sequential equipped with Rh anode X-ray tube. The mineralogy of the samples was determined by X-ray diffraction (XRD) analysis using Shimadzu MAXima XRD-7000 diffractometer with a $\mathrm{Cu} \mathrm{K} \alpha$-radiation $(\lambda=1.54 \AA, 40 \mathrm{kV}, 40 \mathrm{~mA})$ at a scan rate of 2 degree $/ \mathrm{min}$ and a $2 \theta$ range of $2^{\circ}$ $7^{\circ}$. The receiving slit used was $0.3 \mathrm{~mm}$ and step scan size 0.02 degree/step.

The produced composites were crushed and sieved down to a diameter of $\leq 250 \mu \mathrm{m}$ prior to characterization experiments using a manual mortar and a micro-filter for sieving. Thermogravimetric analysis (TGA) was used to investigate the thermal stability and dehydration of the composites prepared from different $\mathrm{NaOH}$ mass ratios by using a NETZSCH (STA 409 PG/PC thermal analyzer). The prepared samples were analyzed promptly by TGA in an isothermal process at $40^{\circ} \mathrm{C}$ for $1 \mathrm{~h}$ to investigate any mass losses that were associated with free or adsorbed water present in the composites. Then about $35 \mathrm{mg}$ of the composite sample was heated from $50^{\circ} \mathrm{C}$ to $1000^{\circ} \mathrm{C}$ at a rate of $10^{\circ} \mathrm{C} \mathrm{min}{ }^{-1}$ under a nitrogen gas atmosphere.

The infrared (IR) spectra were obtained for the composites prepared from different $\mathrm{NaOH}$ mass ratios using a thermo scientific Nicolet spectrometer (Thermo Scientific Smart iTR-IS50R), coupled with an attenuated total reflectance diamond crystal unit. The IR spectra were collected and averaged over 32 total scans from 4000 to $650 \mathrm{~cm}^{-1}$ at a resolution of $2 \mathrm{~cm}^{-1}$.

The morphology of the prepared composites was evaluated by using scanning 
electron microscope (SEM, FEI Inspect, F50/FEG) coupled with a Bruker AXS/EDS system. The SEM micrographs were obtained on platinum-coated specimens using Quorum-Emitech K550X sputter coater at $6 \times 10^{-4} \mathrm{~Pa}$ with $30 \mathrm{kV}$ accelerating voltage.

\subsection{Electrical Conductivity Measurements}

The composite samples were subjected to electrochemical current-voltage (I-V) characterization at room temperature using (EG\&G) Princeton Applied Research scanning potentiostat (Model 362, USA) instrument with a two-electrode system interfaced to computer software for control and data acquisition. The potential window used was between -0.9 and $+1.7 \mathrm{~V}$ and a scan rate of $50 \mathrm{mV} / \mathrm{S}$ was used in this measurement. The inorganic polymer specimens were connected to the potentiosatat electrodes and their electrical conductivities were measured.

The thickness of the specimens was measured by using a digital caliber. The electrical conductivity $\rho$ was calculated according to the following Equations (1) and (2):

$$
\begin{gathered}
I=V / R \\
\rho=R A / l
\end{gathered}
$$

where $R$ is the electrical resistance, $l$ is the length of the cylindrical specimens and $A$ is the cross-sectional area of the cylindrical specimen, $V$ is the applied voltage and $I$ is the measured current.

\section{Results and Discussions}

The TGA curves of the prepared composite materials showed that the major mass loss steps occurred above $500^{\circ} \mathrm{C}$ (Figure $1(\mathrm{~A})$ and Figure $1(\mathrm{~B})$ ). The derivative curves are also shown here to give a better comparison among the samples. The first mass loss located at $70^{\circ} \mathrm{C}$ is nearly identical for graphite and the composites which attributed to free or adsorbed water. The second mass loss step started from $400^{\circ} \mathrm{C}$ to $700^{\circ} \mathrm{C}$ is attributed to the de-hydroxylation of un-reacted kaolinite. The magnitude of this broad peak is found to be increasing with the increase in $\mathrm{NaOH}$ concentration up to $800^{\circ} \mathrm{C}$, indicating a full transformation of kaolinite samples during the alkali activation [4].

The IR spectra in Figure 2(A) and Figure 2(B) show remarkable differences in the three main wave numbers regions:

The bands located at 650,750 and $780 \mathrm{~cm}^{-1}$ are corresponding to the $\mathrm{Al}-\mathrm{O}$ bending mode of $\mathrm{AlO}_{6}$ octahedra in kaolinite [24] [25]. They showed a reduction in the peak intensity which reveals the disintegration of the genuine octahedral structure of the kaolinite particles [4]. Two distinctive weak absorption bands appeared at 730 and $660 \mathrm{~cm}^{-1}$. These two bands are associated with zeolitic phases in the composite, which were reported for the bands observed at 731 and $658 \mathrm{~cm}^{-1}$ [26] [27]. 

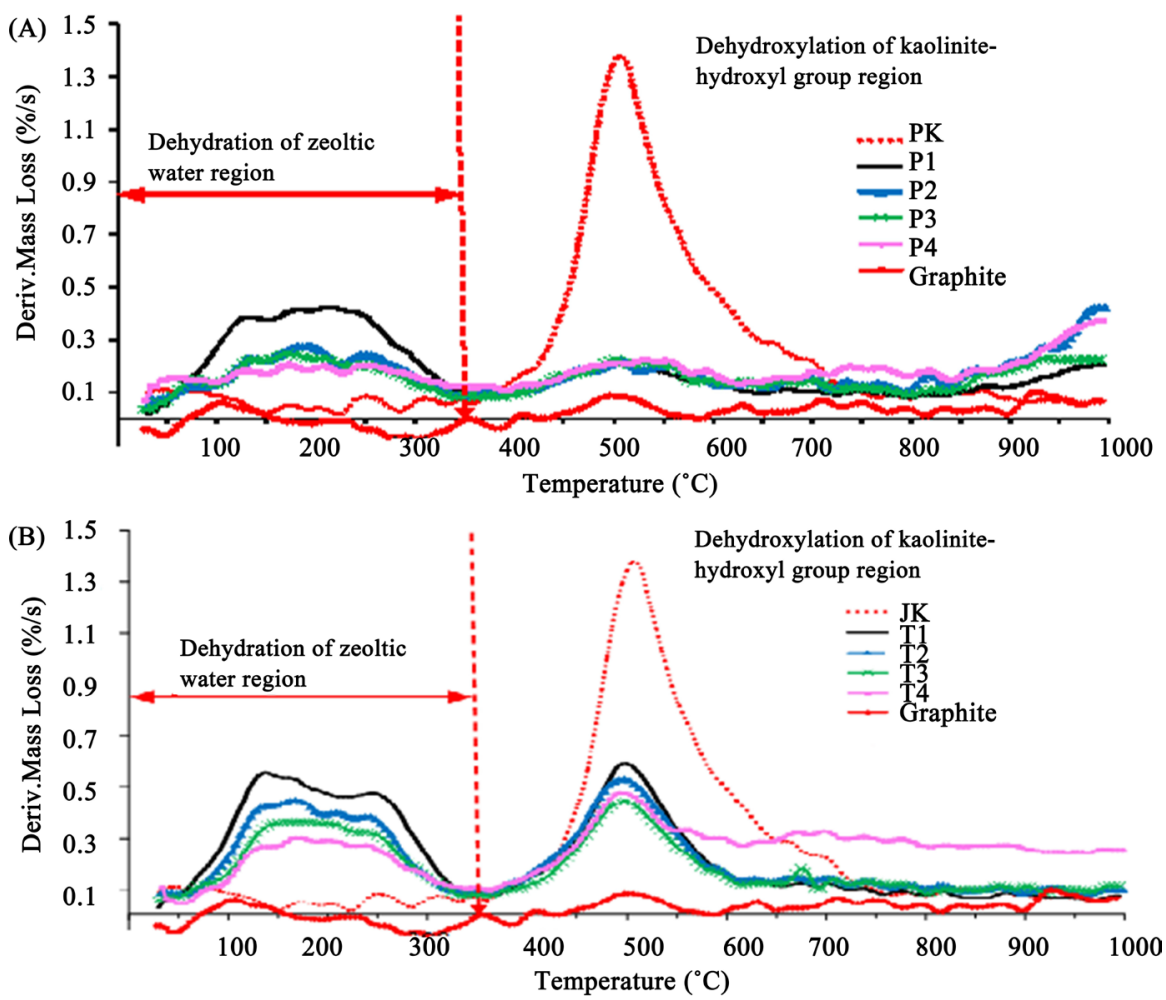

Figure 1. (A) TGA curves of untreated clay PK, graphite and different H-SOD/Graphite composites mass ratios (P1, P2, P3, P4). (B) TGA curves of untreated clay JK, graphite and different $\mathrm{H}-\mathrm{SOD} / \mathrm{Graphite}$ composites mass ratios (T1, T2, T3, T4).

The asymmetric stretching bands due to $\mathrm{Si}-\mathrm{O}-\mathrm{T}(\mathrm{T}=\mathrm{Al}$ or $\mathrm{Si}$ ) in the kaolinite are appearing quite broad in IR since four peaks located at 1111, 1025, 1000 and $910 \mathrm{~cm}^{-1}$ are overlapped into a single peak at $978 \mathrm{~cm}^{-1}$. This band is attributed to the antisymmetric stretching of Si-O-Al bonds in $\mathrm{TO}_{4}$ tetrahedra and is consistent with the band that was reported for the H-SOD [4] [28]. The bands observed at 3958, 3648 and $3625 \mathrm{~cm}^{-1}$ are associated with the stretching of hydroxyl group in kaolinite [29]. The intensity of these bands decreases significantly with increasing $\mathrm{NaOH}$ mass percent in the solution and the bands dissipate at a $\mathrm{NaOH}$ mass ratio of 0.4 for the PK sample and 0.3 for the JK sample, indicating a full conversion of kaolinite particles into a new phase [4].

The crystalline structure of the composites was examined by XRD. The XRD data confirmed that the graphite chains were aligned with the clay layers of the kaolinite in the composite. Figure 3 shows X-ray diffraction patterns for (a) pure kaolinite, (b) 0.25 graphite/PK (c) 0.5 graphite/PK (d) 0.75 graphite/PK, and (e) 1.00 graphite/PK mass ratios (with different $\mathrm{NaOH} /$ clay concentrations for all the composites) (f) graphite, respectively. All the XRD patterns show crystalline phases formed in the composites as indicated by the sharp peaks. The reflection peak at $12.2^{\circ}$ ( $2 \theta$ value) of the composites was shifted towards a higher at $14.2^{\circ}$ which suggests the formation of $\mathrm{H}$-SOD that will interact with graphite to form the final conductive composite [4] [30].

The chemical compositions of PK and JK samples are listed in Table 2. The 
PK powder is composed mainly of $47.8 \% \mathrm{SiO}_{2}$ and $36.1 \% \mathrm{Al}_{2} \mathrm{O}_{3}$ that makes it suitable for H-SOD synthesis [14].

The SEM images and EDX results of the graphite and the kaolinite-based $\mathrm{H}-\mathrm{SOD}$ samples synthesized at different $\mathrm{NaOH} /$ kaolinite mass ratios are shown in Figure 4. The SEM image of the graphite powder (Figure 4(A)) shows the presence of carbon and oxygen atoms, as determined by the EDX spot analysis. Figure 4(B) and Figure 4(C) illustrate that the reaction between graphite powder and different $\mathrm{NaOH} /$ kaolinite mass ratios caused an evolution of a new
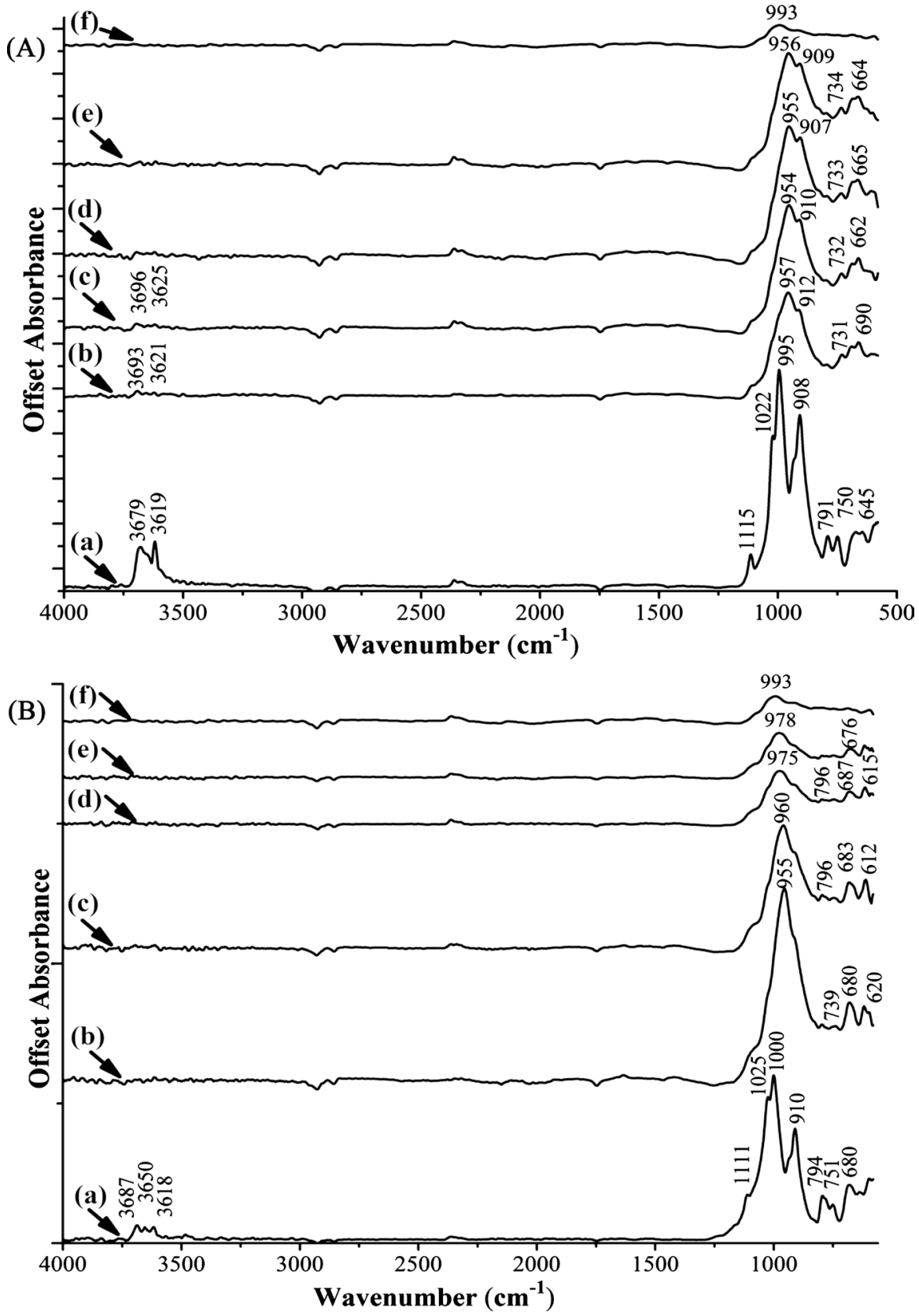

Figure 2. (A) IR spectrums for (a) PK and different H-SOD/graphite composites which are (b) P1, (c) P2, (d) P3, (e) P4 and (f) graphite. (B) IR spectrums for (a) JK and different H-SOD/graphite composites which are (b) T1 (c) T2 (d) T3 (e) T4 and (f) graphite. 


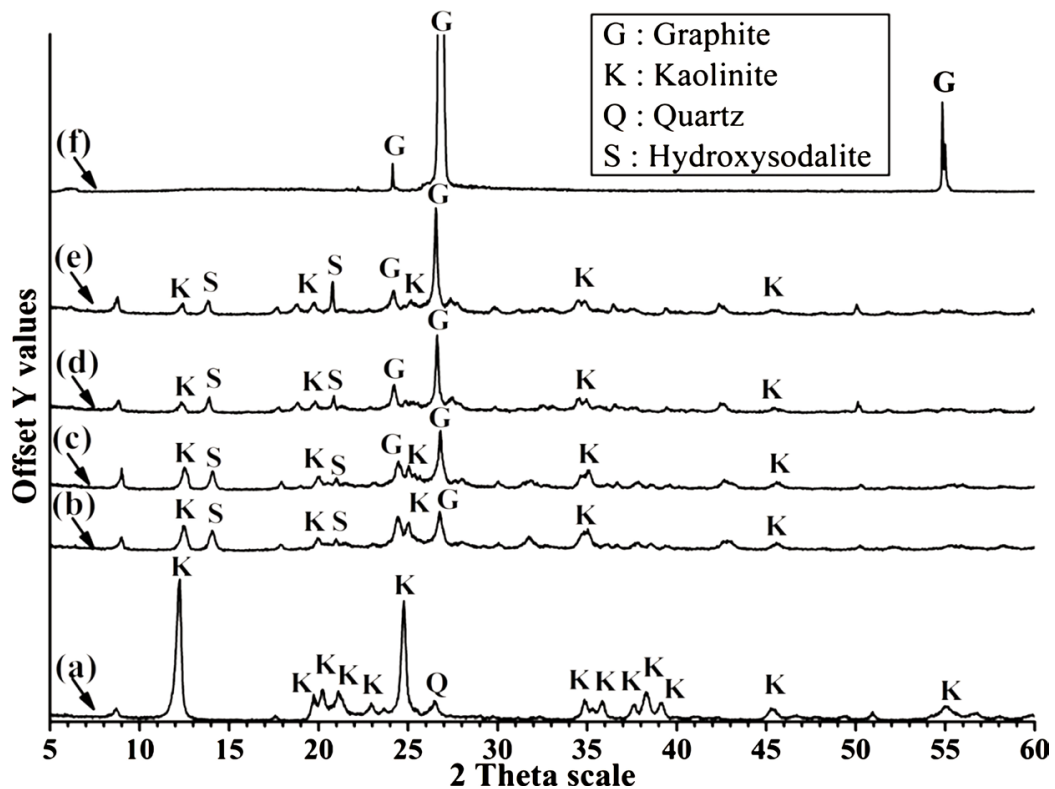

Figure 3. XRD patterns of (a) pure kaolinite (PK) (b) pure kaolinite (PK) based $\mathrm{H}$-SOD/graphite composites with 0.5 graphite/kaolinite mass ratio (P2) (c) PK based $\mathrm{H}-\mathrm{SOD} /$ graphite composites with 1.00 graphite/kaolinite mass ratio (P4) (d) Jordanian kaolinite based H-SOD/graphite composites with 0.5 graphite/kaolinite mass ratio (T2), (e) Jordanian kaolinite based H-SOD/graphite composites with 1.00 graphite/kaolinite mass ratio (T4) and (f) graphite.

Table 2. Chemical composition (wt\%) of Pure Kaolinite (PK) and Jordanian kaolinite (JK).

\begin{tabular}{cccccccccccc}
\hline Material & $\mathrm{Al}_{2} \mathrm{O}_{3}$ & $\mathrm{SiO}_{2}$ & $\mathrm{CaO}$ & $\mathrm{Fe}_{2} \mathrm{O}_{3}$ & $\mathrm{~K}_{2} \mathrm{O}$ & $\mathrm{MgO}$ & $\mathrm{MnO}$ & $\mathrm{TiO}_{2}$ & $\mathrm{Na}_{2} \mathrm{O}$ & L.O.I & Total \\
\hline $\mathrm{PK}$ & 36.1 & 47.8 & 0.1 & 0.8 & 1.4 & 0.2 & 0.3 & 1.2 & 0.1 & 11.6 & 99.6 \\
$\mathrm{JK}$ & 28.6 & 50.1 & 0.2 & 6.1 & 1.1 & 0.5 & 0.4 & 0.6 & 0.2 & 11.9 & 99.7 \\
\hline
\end{tabular}

phase of H-SOD in the composites. H-SOD crystallites accumulated and bonded to the reacted surface of the composite. Figure 4(C) illustrates that the surface of the synthesized material is homogeneously covered by H-SOD nano-particles when Jordanian kaolinite was used in the composite preparation. The H-SOD/graphite particles are linked with each other and aggregate to form porous structure on the surface of the material. The composite aggregates are less than $5 \mu \mathrm{m}$ in diameter, while the single crystallite diameter of the composite is about $700 \mathrm{~nm}$ [4].

The electrical conductivity of the composites, obtained from using $0.25,0.50$, 0.75 and 1.00 mass ratios of graphite-to-kaolinite, was measured. Figure 5 shows the variation of the electrical conductivity with increasing the mass ratio of graphite-to-kaolinite. The electrical conductivities of both kaolinite based composites increased when increasing the graphite-to-kaolinite mass ratio. It was also observed that 1:1 graphite:PK composite showed the highest electrical conductivity value of $3 \times 10^{-3} \mathrm{~s} / \mathrm{cm}$ among all graphite:PK ratios. When 1:1 graphite:JK ratio was used, the conductivity of the composite even reached $1.6 \mathrm{~s} / \mathrm{cm}$. 

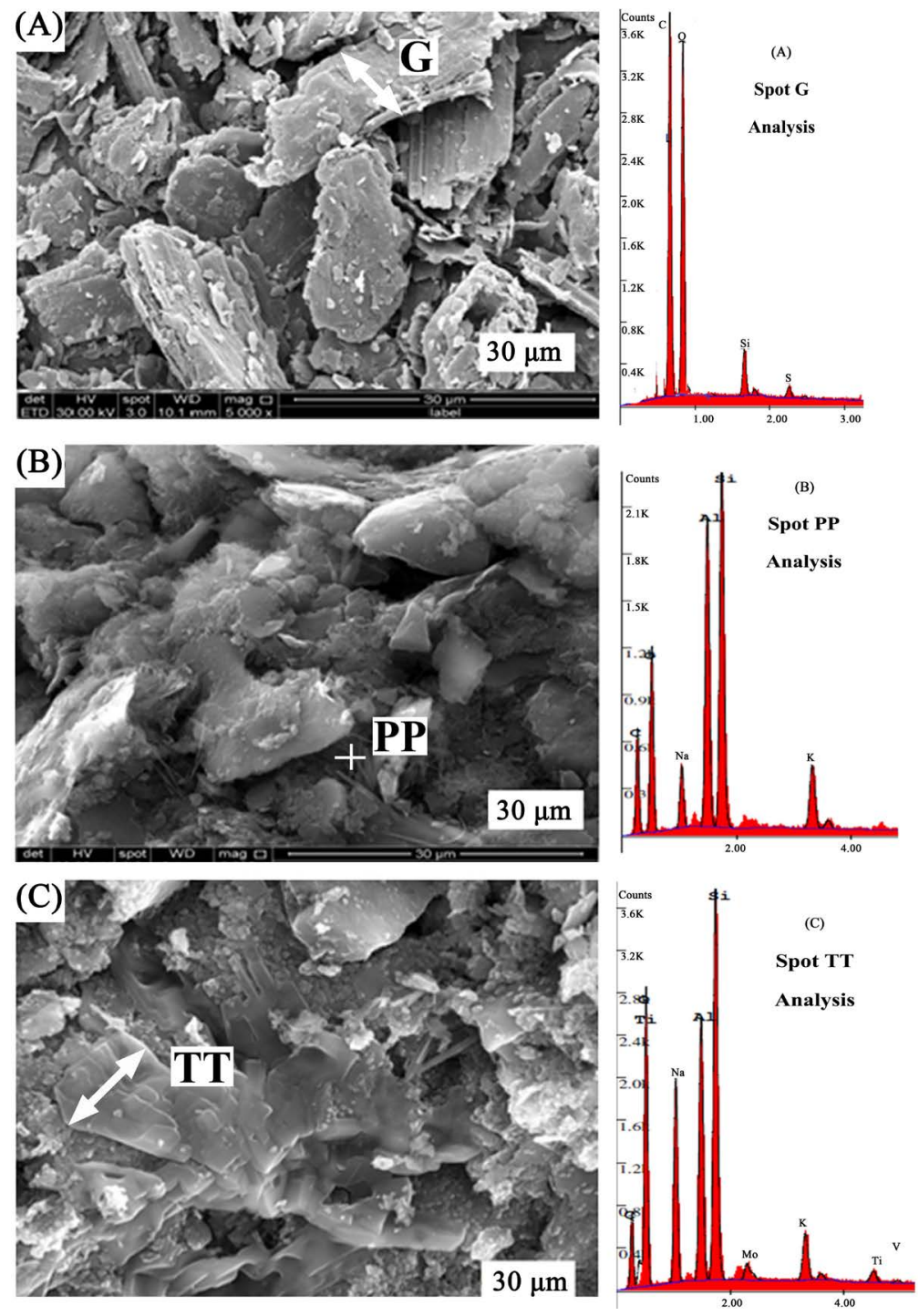

Figure 4. SEM images of (A) graphite (B) pure kaolinite based H-SOD/graphite composite synthesized using different $\mathrm{NaOH} / \mathrm{clay}$ mass ratio (C) Jordanian kaolinite based H-SOD/graphite composite synthesized using $0.4 \mathrm{NaOH} /$ clay mass ratio.
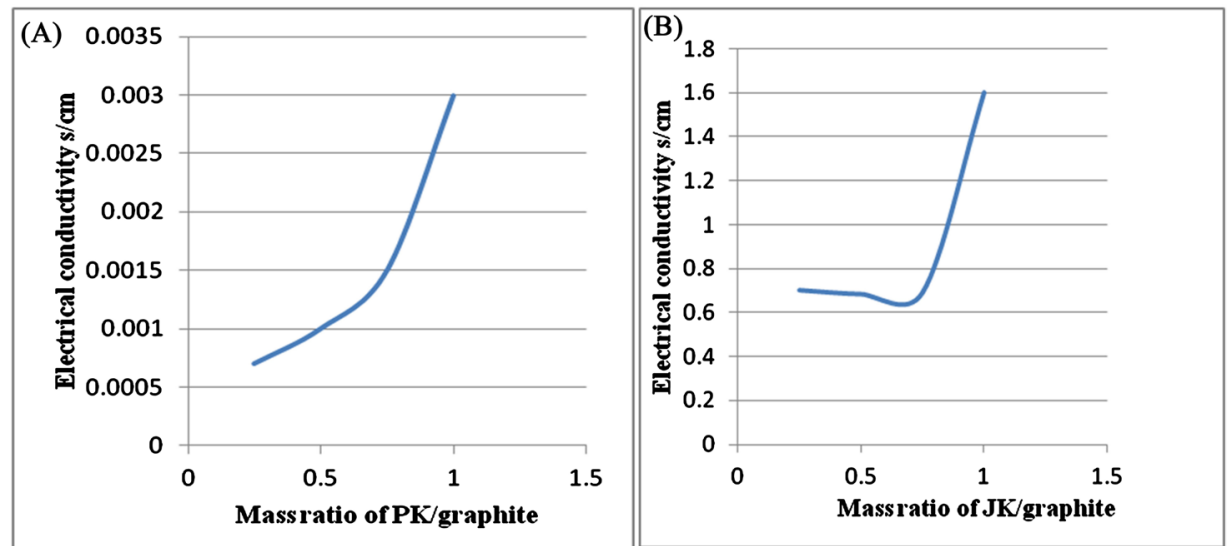

Figure 5. Values of electrical conductivity for different (a) pure kaolinite based H-SOD/graphite composite mass ratios synthesized using different $\mathrm{NaOH} /$ kaolinite mass ratio (C) Jordanian kaolinite based $\mathrm{H}$-SOD/graphite composite mass ratios synthesized using different $\mathrm{NaOH} /$ kaolinite mass ratio. 


\section{Conclusion}

Electroconductive hydroxy-sodalite/graphite composites were successfully synthesized by alkali-activation of Jordanian or pure kaolinite clay (JK and PK, respectively) in the presence of graphite as a conductive phase. The X-ray diffraction results demonstrated that the intercalation of conducting graphite materials with JK or PK layers occurred in the composite structure formation. The FTIR study also showed the successful incorporation of graphite in the clay structure. The electrical conductivity of the composites increased with the increase in graphite percentage in the composite.

\section{Acknowledgements}

This work is supported by The Jordanian Scientific Research Support (SRSF) under the grant number Bas/2/9/2016.

\section{Conflicts of Interest}

The authors declare no conflicts of interest regarding the publication of this paper.

\section{References}

[1] Rahimi, A. (2003) Inorganic and Organometallic Polymers: A Review. Iranian Polymer Journal, 13, 149-164.

[2] Srivastava, S. and Gadhave, R. (2015) Recent Developments in Inorganic Polymers: A Review with Focus on Si-Al Based Inorganic Polymers. Oriental Journal of Chemistry, 31, 2475-2480. https://doi.org/10.13005/ojc/310483

[3] Perry D. (2011) Handbook of Inorganic Compounds. CRC Press, Boca Raton. https://doi.org/10.1201/b10908

[4] Esaifan, M., Rahier, H., Barhoum, A., Khoury, H., Hourani, M. and Wastiels, J. (2015) Development of Inorganic Polymer by Alkali-Activation of Untreated Kaolinitic Clay: Reaction Stoichiometry, Strength and Dimensional Stability. Construction and Building Materials, 91, 251-259. https://doi.org/10.1016/j.conbuildmat.2015.04.034

[5] Olwale, D. (2013) Syntheses, Characterization and Binding Strength of Geopolymers: A Review. International Journal of Materials Science and Applications, 2, 185-193. https://doi.org/10.11648/j.ijmsa.20130206.14

[6] Jha, B. and Singh, D. (2012) Zeolitization Characteristics of a Fly Ash from Wetand Dry-Disposal Systems. Acta Geotechnical Slovenica, 2, 63-71.

[7] Scott, M., Kathleen, A. and Dutta, P. (2003) Handbook of Zeolite Science and Technology. CRC Press, New York.

[8] Jiang, J.X., Yu, J.H. and Corma, A.C. (2010) Extra-Large-Pore Zeolites: Bridging the Gap between Micro and Mesoporous Structures. Angewandte Chemie, 49, 3120-3145. https://doi.org/10.1002/anie.200904016

[9] Gabrus, E., Nastaj, J., Tabero, P. and Aleksandrzak, T. (2015) Experimental Studies on 3A and 4A Zeolite Molecular Sieves Regeneration in TSA Process: Aliphatic Alcohols Dewatering-Water Desorption. Chemical Engineering Journal, 259, 232-242. https://doi.org/10.1016/j.cej.2014.07.108 
[10] Galadima, A. and Muraza, O. (2015) Role of Zeolite Catalysts for Benzene Removal from Gasoline via Alkylation: A Review. Microporous and Mesoporous Materials, 213, 169-180. https://doi.org/10.1016/j.micromeso.2015.02.029

[11] Gómez-Hortigüela, L., Pinar, A.B., Pérez-Pariente, J., Sani, T., Chebude, Y. and Díaz, I. (2014) Ion-Exchange in Natural Zeolite Stilbite and Significance in Defluoridation Ability. Microporous and Mesoporous Materials, 193, 93-102. https://doi.org/10.1016/j.micromeso.2014.03.014

[12] Sharma, P., Song, J., Han, M. and Cho, C. (2016) GIS-NaP1 Zeolite Microspheres as Potential Water Adsorption Material: Influence of Initial Silica Concentration on Adsorptive and Physical/Topological Properties. Scientific Reports, 6, 1-26. https://doi.org/10.1038/srep22734

[13] Fornefett, I., Rabet, D., Buttersack, C. and Buchholz, K. (2016) Adsorption of Sucrose on Zeolites. Green Chemistry, 18, 3378-3388.

https://doi.org/10.1039/C5GC02832A

[14] Esaifan, M., Hourani, M., Khoury, H., Rahier, H. and Wastiels, J. (2017) Synthesis of Hydroxysodalite Zeolite by Alkali-Activation of Basalt Powder Rich in Calc-Plagioclase. Advanced Powder Technology, 28, 473-480. https://doi.org/10.1016/j.apt.2016.11.002

[15] Moulson, A. and Herbert, J. (2003) Electroceramics; Materials, Properties, and Applications. John Wiley, New York.

[16] Sengupta, R., Bhattacharya, M., Bandyopadhyay, S. and Bhowmick, A. (2011) A Review on the Mechanical and Electrical Properties of Graphite and Modified Graphite Reinforced Polymer Composites. Progress in Polymer Science, 36, 638-670. https://doi.org/10.1016/j.progpolymsci.2010.11.003

[17] Dresselhaus, M. and Dresselhaus, G. (1981) Intercalation Compounds of Graphite. Advances in Physics, 51, 1-186. https://doi.org/10.1080/00018730110113644

[18] Chung, D. (2002) Review Graphite. Journal of Materials Science, 37, 1475-1489. https://doi.org/10.1023/A:1014915307738

[19] Pierson, H. (1994) Handbook of Carbon, Graphite, Diamonds and Fullerenes Processing, Properties and Applications. Noyes Publications, Park Ridge.

[20] Mei, H., Xu, Y., Sun, Y., Bai, Q. and Cheng, L. (2016) Carbon Nanotube Buckypaper Reinforced SiCN Ceramic Matrix Composites of Super Electrical Conductivity. Journal of European Ceramic Society, 36, 1893-1898. https://doi.org/10.1016/j.jeurceramsoc.2016.02.045

[21] Bard, A. and Faulkner, L. (2001) Electrochemical Methods: Fundamentals and Applications. John Wiley, New York.

[22] Bowen, C., Adamaki, V. and Thomas, T. (2014) Manufacture of Porous Electrically Conductive Ceramics. Proceedings of the International Conference on Mining. Material and Metallurgical Engineering, Prague, 11-12 August 2014, Vol. 1, 1-8.

[23] Corb, I., Manea, F., Radovan, C., Pop, A., Burtica, G., Malchev, P., Picken, S. and Schoonman, J. (2007) Carbon-Based Composite Electrodes: Preparation, Characterization and Application in Electroanalysis. Sensors, 7, 2626-2635. https://doi.org/10.3390/s7112626

[24] Kristof, J., Mink, J., Horvath, E. and Gabor, M. (1993) Intercalation Study of Clay Minerals by Fourier Transform Infrared Spectrometry. Vibrational Spectroscopy, 5, 61-67. https://doi.org/10.1016/0924-2031(93)87055-X

[25] Tarte, P. (1976) Infra-Red Spectra of Inorganic Aluminates and Characteristic Vibrational Frequencies of $\mathrm{AlO}_{4}$ Tetrahedra and $\mathrm{AlO}_{6}$ Octahedra. Molecular Spec- 
troscopy, 23, 2127-2143.

[26] Alkan, M., Hopa, C., Yilmaz, X. and Guler, H. (2005) The Effect of Alkali Concentration and Solid/Liquid Ratio on the Hydrothermal Synthesis of Zeolite NaA from Natural Kaolinite. Microporous and Mesoporous Material, 86, 176-184. https://doi.org/10.1016/j.micromeso.2005.07.008

[27] Flaningen, M., Khatami, A. and Szymanski, A. (1971) Molecular Sieve Zeolites. Advances in Chemistry Series, 101, 201-227.

[28] Mclellan, B., Williams, R., Lay, J., Riessen, A. and Corder, G. (2011) Costs and Carbon Emissions for Geopolymer Pastes in Comparison to Ordinary Portland Cement. Journal of Cleaner Production, 19, 1080-1090. https://doi.org/10.1016/j.jclepro.2011.02.010

[29] Kani, E., Allahverdi, A. and Provis, J. (2012) Efflorescence Control in Geopolymer Binder Based on Natural Pozzolan. Cement and Concrete Composites, 34, 25-33. https://doi.org/10.1016/j.cemconcomp.2011.07.007

[30] Anuar, K., Murali, S., Fariz, A. and Ekramul, M. (2004) Conducting Polymer/Clay Composites: Preparation and Characterization. Materials Science, 10, 255-258. 